\title{
EGFRvIII Peptide
}

National Cancer Institute

\section{Source}

National Cancer Institute. EGFRvIII Peptide. NCI Thesaurus. Code C29017.

A synthetic peptide sequence derived from the tumor specific mutant variant of epidermal growth factor receptor EGFRvIII orig inally found in glioblastoma multiforme, caused by the deletion of exons 2-7. Unlike wild-type EGFR, EGFRvIII is a dominant oncogene that can directly lead to cancer. EGFRvIII is expressed in multiple cancer types including breast, ovarian, and metastatic prostate cancers, and other types of solid tumors due to alternative splicing; has not been observed in normal human tissues. Vaccination with EGFRvIII peptide may stimulate the host immune system to mount a cytotoxic T lymphocyte response against tumor cells positive for EGFRvIII, resulting in decreased tumor growth. ( $\mathrm{NCl04)}$ 